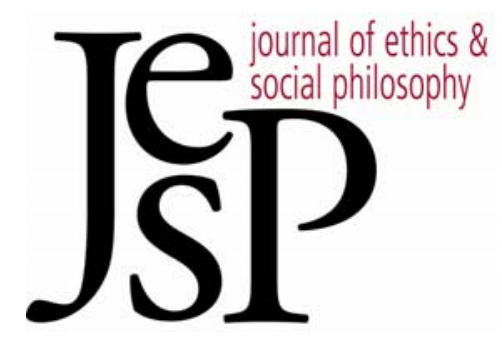

\title{
SAVINg PeOPle and Flipping CoINS
}

\author{
BY BEN BRADLEY
}

Journal of Ethics \& Social Philosophy

VOL. 3, NO. 1 | MARCH 2009 URL: WWW.JESP.ORG COPYRIGHT (C) BEN BRADLEY 2009 


\section{Saving People and Flipping Coins ${ }^{1}$ \\ Ben Bradley}

$\mathrm{S}$ UPPOSE YOU FIND YOURSELF IN A situation in which you can either save both A and B, or save only C. A, B and C are relevantly similar - all are strangers to you, none is more deserving of life than any other, none is responsible for being in a life-threatening situation, and so on. John Taurek argued that when deciding what to do in such a situation, you should flip a coin, thereby giving each of A, B and C a 50 percent chance of survival (Taurek 1977: 303). Only by doing this can we treat each person with the appropriate degree of respect. Taurek seemed to be employing the "Equal Greatest Chance" principle (EGC), according to which, when deciding whom to save, one must give each person the greatest possible chance of survival consistent with everyone else having the same chance. An obvious alternative (not the only one) is the "Save the Greater Number" principle (SGN), which needs no elaboration.

There has been robust discussion of this sort of example in recent years. ${ }^{2}$ This discussion has usually focused on the question of whether it is permissible to aggregate claims. In what follows, I ignore most of this interesting discussion. I describe an example that shows that EGC is false. I show that the example also demonstrates the falsity of other related views, including Jens Timmermann's "Individualist Lottery Principle" (ILP). I conclude that SGN is true. And I extend the argument to other kinds of cases, showing that which person should be saved may depend on whether some additional wellbeing may be gained for someone in the process.

Some preliminaries are in order. First, note that EGC and SGN are principles that emerge far downstream of the level of general criteria for moral rightness. They apply only to the particular sort of situation just described, and it is not obvious how one should generalize to other sorts of situations. Each principle might be supported by any number of general criteria. SGN follows most obviously from utilitarianism, but is also accepted by, among others, contractualist T.M. Scanlon (1998: 234). Wasserman and Strudler (2003) have argued that nonconsequentialists have failed to make the case that SGN is compatible with the rejection of consequentialism. If they are right, then we must choose between two competing packages: a consequentialist moral theory that entails SGN, and a nonconsequentialist one that entails EGC or some variant. I won't take a stand here on whether Wasser-

1 Thanks to Mike Almeida, Campbell Brown, Jamie Dreier, Caspar Hare, John Hawthorne, Matthew Liao, Doug Portmore and Mike Titelbaum for discussion. For more discussion, see http://peasoup.typepad.com/peasoup/2005/12/saving_the_grea/comments/.

2 Frances Kamm (2000), T.M. Scanlon (1998) and Iwao Hirose (2001) argue against EGC; Michael Otsuka (2000) and Wasserman and Strudler (2003) argue against Kamm and Scanlon; Kamm (2006) and Rahul Kumar (2001) respond to Otsuka; Rob Lawlor criticizes EGC but defends a Taurekian insight; Jens Timmermann (2004) argues against Hirose (2001) and for a sort of weighted lottery; and Hirose (2007) argues against weighted lotteries. 
man and Strudler are right. But I will say that it would be a mistake to allow phobia of all things that smell vaguely utilitarian to cause us to resist a knockdown argument for SGN.

Second, note an important difference between SGN and EGC. SGN is a principle about what the agent should do in the end: save the greater number. EGC is a principle that is at least partly about how one should decide what to do in the end: flip a coin. It is also a principle about what to do in the end: whatever the coin says to do. We might say that EGC, unlike SGN, is partly a decision procedure rather than a criterion of rightness. But I think it is more helpful to see both principles as evaluating complex courses of action that an agent may engage in when confronted with this sort of situation where action is understood to include deliberative procedures such as coinflippings. SGN evaluates these courses of action by looking only at one feature: how many people are saved? The agent can flip a coin, sing a song or whatever she likes, as long as the greater number is saved. EGC evaluates these courses of action according to the deliberative process used (e.g., a coin flip) and its fit with the action done subsequently. One is permitted to save the greater number only if the coin flip says to do so. But more than that, the coin flip must be what guides the decision. It's not enough to flip a coin and then coincidentally do what the coin says to do. Imagine, for instance, that Raul finds himself in just such a situation. Raul decides to flip a coin to decide whether to save the larger or smaller group. The coin comes up heads, indicating that the larger group should be saved. But Raul then decides that coin-flipping is silly. He decides to save the greater number, not because the coin tells him to, but because he now believes utilitarianism to be true. I take it that the EGC defender will say Raul does something wrong, even though he flips a coin and does the action the coin indicates he should do.

Third, the notion of chance is essential to EGC. Is this objective chance or subjective chance? ${ }^{3}$ There might be reasons to go either way. Against objective chance, suppose that determinism is true. Then the objective chance that any given individual will be saved will be either zero or one. EGC blows a fuse. But surely EGC is not supposed to presuppose that determinism is false. Against subjective chance, suppose an agent believes she possesses a fair coin, which she uses to determine whom to save. But as it happens, the coin is weighted. One of the people really had no chance to be saved. Wouldn't the EGC defender wish to say that that person received unfair treatment? It is not clear to me how best to understand the notion of chance required by EGC. But I don't believe my argument turns on which way EGC is understood.

Finally, I must point out that versions of the main example I discuss have been floating around for at least twenty years. Similar examples are described by John T. Sanders and Judith Thomson, but neither finds sufficient

${ }^{3}$ Thanks to Caspar Hare for discussion of this point. 
reason to reject EGC. ${ }^{4}$ I mention this to give credit where credit is due, but also because I find it puzzling that the import of the example has not been appreciated.

\section{Bureaucracy and EGC}

Here is the example. Batman believes in EGC, and never leaves home without a fair coin. Batman's nemesis, a murderous bureaucrat named the Joker, has captured three hostages, named Alice, Bob and Carol. The Joker tells Batman the following: "I am going to divide these three hostages randomly into two groups - a group of two and a group of one. I will let you determine which group you wish to save, and I will kill only the members of the other group. Indicate your decision by filling out this form, and checking the appropriate box." As a believer in EGC, Batman would choose to save the larger group, since that decision gives each a two-thirds chance of survival, and nothing else gives each person a greater chance. If Batman were to flip a coin to decide whether to save the larger or the smaller group, he would diminish each person's chance of survival to one-half. So far, EGC and SGN get the same results.

At noon, Batman checks the box indicating that the larger group should be saved. The Joker proceeds to divide the hostages randomly into two groups. Alice and Bob are in one group, Carol is in the other. At 1:00, the Joker realizes he has lost the form. "I'm sorry, Batman, but you'll have to fill out another form," he says. If Batman is to follow EGC, at 1:00 he must flip a coin to decide which box to check, since that gives each hostage an equal greatest chance of survival.

This is a decisive counterexample against EGC. No plausible principle entails that Batman should fill out the form differently at 1:00. He knew at noon that this was one way things might turn out. By 1:00 he has gained no new information that could be relevant to his decision. ${ }^{5}$ The point here is not merely that Batman should not flip a coin at 1:00. If that were the point, the EGC defender could accuse me of dialectical incompetence. Rather, the point is that it cannot be the case that Batman should fill out the form differently at the two times.

${ }^{4}$ See Thomson (1990: 181-197) and Sanders (1988: 5n). Thomson's example involves a distinction between killing and letting die. Perhaps for that reason, Thomson does not take her example to show that EGC is false; she claims it is permissible for the character in her example either to save the greater number or to employ EGC (1990: 197). Like Thomson, Sanders does not conclude that his example refutes EGC; he merely says that "the mind reels" when contemplating these sorts of cases and that Taurek can get around the problem by, I suppose, denying that EGC applies to such cases (1988: 5n). It seems to me the only reason Taurek would be entitled to say that EGC does not apply to my example is that he endorses the objection to premise 3 discussed and rejected below.

${ }^{5}$ Cf. Thomson (1990: 194-5). 
Showing that EGC is false is not sufficient to show that SGN is true. But this example serves both purposes, for it refutes any principle that permits Batman to risk saving the smaller number.

Consider, for example, Jens Timmermann's “individualist lottery" principle (ILP). Here is what Timmermann says about the classic case where A is on one island and $\mathrm{B}$ and $\mathrm{C}$ are on another, and a rescuer can only reach one island to save its inhabitants:

To give the claims of $\mathrm{A}, \mathrm{B}$ and $\mathrm{C}$ equal weight, a coin will not do. We need a wheel of fortune with three sectors, each of which bears the name of one islander. The person whose sector comes up is saved. If this person is A, both B and C perish. If B's sector is selected, B is saved. Having reached the island, the rescuer then incurs an obligation to save C. Similarly, if C wins B is also saved. (Timmermann 2004: 110)

In the Batman story, ILP entails that at 1:00, Batman must spin a wheel of fortune, giving Alice and Bob a two-thirds chance of survival and Carol a one-third chance.

What ILP entails that Batman must do at noon is unclear. Perhaps it entails that Batman should spin the wheel of fortune. Since Batman does not yet know who is in the larger group and who is in the smaller one, he cannot assign names to the sectors on the wheel, for this will not tell him whether to save the larger or smaller group. Rather, he must assign placeholders to each of the segments on the wheel of fortune, indicating whether that segment is inhabited by a member of the larger or smaller group - two segments would get a larger group designation, one segment would get a smaller group designation. This would result in a two-thirds chance that the larger group would be saved, and a one-third chance that the smaller group would be saved.

But to spin a wheel in this case would be to fetishize the wheel. At noon, all three hostages prefer that Batman choose to save the larger group. To spin the wheel would be to reduce each person's chance of survival from two-thirds to five-ninths - not quite as bad as the EGC, but still unacceptable.

Perhaps ILP does not require Batman to do any wheel-spinning at noon. If so, then ILP goes wrong in just the way EGC goes wrong: it requires Batman to behave differently depending on what time it is, for once the hostages are divided into groups, ILP surely entails that the wheel must be spun. So it seems that whatever ILP says about this case, it goes wrong in some way.

A similar example also refutes a view proposed by Rob Lawlor (2006). Lawlor claims that whether we should toss a coin or simply save the greater number depends on the numbers involved. According to Lawlor, some value attaches to the act of giving each person a chance to survive; but when the discrepancy in numbers between the two groups is sufficiently great, that value is outweighed by the negative value of allowing additional people to die (Lawlor 2006: 160). Lawlor's view gives the same results as SGN in many cases, but differs in cases involving large numbers on both sides: 
In the case where we can save one, or we can save two, the extra life we can save is weighed against the moral value of giving one person - the lone individual - some chance of survival. In the case where we can save $1,000,000$ or we can save $1,000,001$, however, the one extra life we can save is weighed against the moral value of giving $a$ million people a chance of survival. (Lawlor 2006: 161)

If Lawlor is right, then in a version of the Batman case in which there are 2,000,001 people involved, to be divided into a group of 1,000,000 and a group of 1,000,001, Batman should, at noon, choose to save the larger group, and at 1:00, flip a coin. And this cannot be right. We must reject the idea that there is value in giving people a chance.

The argument may be summarized as follows:

1. At noon, it is morally obligatory to save the greater number.

2. If, at noon, it is morally obligatory to save the greater number, then, at 1:00, it is morally obligatory to save the greater number.

3. If it is obligatory to save the greater number both at noon and at 1:00, then SGN is true.

4. Therefore, SGN is true.

It would be nice to be able to appeal to some general principle in order to give a convincing justification for premise 1. For example, we might attempt to justify premise 1 by appeal to a general moral theory. A contractualist like Scanlon must accept it, since everyone involved can and would reasonably reject any principle that permits Batman to do anything other than save the greater number at noon. A Kantian must accept it too, I think, for it is impossible to see how one may show respect for Alice, Bob and Carol by doing anything other than save the greater number. (Imagine the three of them begging Batman to choose the greater number, and imagine Batman replying: "I'm morally obligated to show respect to all of you as rational beings, and this requires me to flip a coin." In the unlikely event that this is what a respect-based moral theory requires, we would be forced to reject the theory.) The fact that some popular moral theories seem to entail the truth of premise 1 might make us feel better about the premise. But it seems to me that premise 1 is far more plausible than contractualism, Kantianism or any other moral theory. The fact that the premise is entailed by those theories merely forestalls some bad objections that could be raised by partisans of those theories. And it is worth reiterating that at least some of SGN's competitors, such as EGC, entail the truth of premise 1.

The same may be said of premise 2; it is just obvious that changing one's mind under these circumstances is irrational, and any principle we might supply to defend the premise will be more dubious than the premise itself. We might wish to appeal to some principle such as this: If it is impermissible to $\Phi$ at time $t 1$, and nothing morally important has changed between $t 1$ and $t 2$ ( $t 2>t 1$ ), 
then it is impermissible to $\Phi$ at time 2 . I don't know whether this principle is true or not. Even if I could be convinced the principle were false, it would not change my verdict about the Batman case. In the interest of preempting bad objections, we might again appeal to a Scanlonian principle, and point out that if Carol were to lodge a complaint against Batman, insisting that he flip a coin or spin a wheel of fortune at 1:00, she would be unreasonable. As evidence for her unreasonableness, it could be pointed out to her that, just an hour ago, she was in favor of Batman's decision to save the greater number. Had she been asked, at noon, what she thought Batman should do in the event Joker lost the form and Batman had to fill it out all over again after the random division, surely her preference would have been that he save the greater number. The only thing that has changed is that, now, she herself is in the smaller group. Carol's misfortune is bad luck, not mistreatment at Batman's hands.

For those who still do not find premise 2 intuitively compelling, I can offer the following. ${ }^{6}$ Suppose that Batman knows, at noon, that the Joker is sometimes incompetent bureaucratically. He knows the Joker might lose the form and, that if he does, he will have to fill out the form again. Only a crazy person would plan at the outset to fill the form out differently at noon and at 1:00 under these conditions. But this minimal bit of knowledge should make no difference to how Batman decides.

It may not be immediately obvious why premise 3 is true. Premise 3 is true because SGN is the only principle that absolutely ensures that Batman may not change his mind. Any principle that requires Batman to follow some decision process to its conclusion and do whatever that process tells him to do might permit him to change his mind and flip a coin or spin a wheel of fortune at 1:00.

\section{Objections}

While I know of no explicit responses to this argument in the literature, there is a very similar argument in the neighborhood: the veil of ignorance argument. Behind a "veil of ignorance" - that is, not knowing what position one will occupy - everyone would prefer a policy whereby the greatest number are always saved, since it would maximize their chance of survival. Thus, here and now we should take that principle to be justified, and save the greater number. This argument is rarely explicitly endorsed, but is occasionally criticized. 7 My argument is similar to the veil of ignorance argument. There are differences. My argument employs an actual veil of ignorance, not a hypothetical one. And I do not appeal to any general principle linking what should

\footnotetext{
6 Thanks to Jamie Dreier for this argument.

7 Taurek discusses this argument (Taurek 312). Kamm criticizes it in Kamm 1993: 119-121 and Kamm 1998: 941. Neither Taurek nor Kamm cite anyone who has endorsed this argument, though of course one suspects Rawls (1971) might have given it.
} 
now be done with what would hypothetically be chosen behind a veil of ignorance. In fact, I do not appeal to any general principle at all! I claim only that in this case, Batman should not change his mind between noon and 1:00. Nevertheless, given the similarities here, we should look at objections to the use of veil of ignorance reasoning applied to such cases, to see whether those objections apply to my argument.

Though she accepts SGN, Kamm rejects the veil of ignorance argument. According to Kamm, the argument "suggests that it would be permissible to kill one who would not otherwise die to save five" (Kamm 1998: 941). The idea is that, behind the veil of ignorance, we would want to institute a policy whereby anyone given the opportunity to save five innocent people by killing an innocent person would do so. But it would be wrong to do so, so there must be something wrong with the veil of ignorance argument. Sometimes acts we would endorse behind a veil of ignorance are morally wrong.

Suppose we agree with Kamm about this. What follows for my argument? As far as I can tell, nothing follows. ${ }^{8}$ Kamm's suggestion, surely, is that the choice we would make behind the veil of ignorance concerning whether to kill one to save five is just wrong. The correct choice is to refuse; the problem is that we wouldn't make the correct choice if we were only looking out for our own self-interest. In the case of my argument, Batman's decision at noon to save the greater number is not only the one anyone would make behind a veil of ignorance; it is also the correct decision. So there is no basis for an objection to premise 1 here.

Does Kamm's point have relevance for premise 2 - does it give any reason to think Batman should change his mind? Well, suppose we alter the Batman example in an obvious way: Joker gives Batman the chance to kill one of the three hostages to save the other two, and which one will be sacrificed is to be determined by Joker's random division of the hostages sometime between noon and 1:00. Suppose we are like Kamm, and we think it is wrong, at 1:00, for Batman to choose to kill the one. Then I presume we will also think it is wrong at noon for him to make that choice. Those who believe in a deontological restriction against killing will see no reason to think it matters whether the hostages have already been divided. So I see no basis here for an objection to premise 2 either. Thus, even if Kamm has given us good reason to reject the veil of ignorance argument, she has not given good reason to reject my argument. (I discuss another of Kamm's points in section 4.)

Some remarks of Timmermann's suggest an objection to premise 1:

While the expectation of survival of someone who does not know which of the two islands he is going to be on is lower for small numbers, when the numbers go up it approximates to the probability yielded by the principle always to save the greatest number. It is rational for the members of a society

8 To be clear, I am not suggesting that Kamm thinks her response would apply to my argument. Her response is to the veil of ignorance argument, not mine. 
not to choose to maximize the probability of being saved. A somewhat lower overall probability is the price they would be willing to pay for their claim's never being discounted right at the beginning.... Our unreflective feeling that the greater number ought to be saved... is just an overgeneralization. (Timmermann 2004: 112)

Applying Timmermann's reasoning to my example, he might suggest that at noon, each of Alice, Bob and Carol would wish to ensure that their future claim to survival is not discounted - that is, they would want to ensure that they retain a chance of being saved later on. The certainty of having that chance, says Timmermann, would be worth increasing the probability of death.

But Timmermann offers no argument that this is a rational tradeoff. Why would Alice prefer that her chance of survival be decreased merely so that, at 1:00, she will retain a chance of survival? The only reason to want to retain that possibility is that survival is valuable to her; if survival is valuable to her, then surely, at noon, she ought to prefer the option that maximizes her probability of survival.

Timmermann notes that as the number of people in the larger group increases, the probability of survival given implementation of ILP approaches the probability of survival given implementation of SGN. It is not clear why he points out this fact. Perhaps the idea is that, when the numbers get very large, it hardly matters to one's chance of survival whether ILP or SGN is implemented; thus, in such situations, people would accept a tiny reduction in survival probability in exchange for ensuring that their claim to survival will never be completely discounted. That is, he might be thinking that given the choice between (A) risking having one's claim to survival disregarded right away, but having a slightly higher chance of survival overall, and (B) ensuring that one's claim to survival will not be disregarded right away, but having a slightly lower chance of survival overall, people would choose (B). This seems implausible, because when the number of people in the larger group is very large, the people in the smaller group will retain only a very tiny chance of survival; if people don't care about the tiny difference in survival probability between ILP and SGN in large-number cases, they shouldn't care about having the certainty of retaining an even tinier probability of survival either. More importantly, this does nothing to show that it would make sense to choose the wheel-spinning method when the numbers are small, as in the Batman case. Thus, I see no reason to reject premise 1.

I can imagine someone objecting to premise 3 in the following way: "What matters is that at some point, Alice, Bob and Carol each had a chance to survive. Granted, it was the Joker rather than Batman who was responsible for this chance, but this doesn't matter; they are treated fairly because each had a chance to be saved as of noon. This is why Batman shouldn't 
change his mind. He should be permitted to consider, in his decision-making process, any past events that gave each individual a chance to be saved.",

This objection is unpersuasive. To see why, just return to the classic case discussed in the literature, where a large group of people is on one island, a small group is on another, and only one group may be saved. Those who defend EGC or a weighted lottery say that we must give the smaller group a chance to be saved, by flipping a coin or spinning a wheel. Now suppose that those people are on those islands because, at some time in the past, each person was on a separate canoe between the two islands, and an indeterministic process involving air and water currents led each canoe to head toward one island or the other. For each canoe, there was a chance that it might go to either island. Thus each person had a chance, at some time in the past, to be in the larger group. If the imagined objection to my argument succeeds, it must be concluded that the larger group must be saved. And it is hard to imagine why the larger group should be saved in this case, but not in the case where their canoes were guided by a deterministic process that ensured that they would end up where they did, or where they got to their respective islands by just about any other means imaginable, such as being placed there by an evil Joker. ${ }^{10}$

So the insistence on giving each person a chance to survive must amount to an insistence that the agent herself, on that occasion, give that chance to the people in question. And this leads to the absurd conclusion that Batman should change his mind.

\section{Extending the Argument}

The argument so far applies only to cases where the only things at stake are people's lives. And most agree that saving the greater number is the right thing to do in such cases. But the argument may be easily extended to give results that some might find more uncomfortable, because they push us farther down the path to utilitarianism. For example, similar cases will refute Kamm's intuitions about whether fingers can be weighed against lives: "We must choose between saving $C$ and saving $D$, and only if we save $D$ can we also reach $\mathrm{E}$ in time to prevent his finger from falling off (Finger Case). There again, I think, we should not deprive $C$ of his 50 percent chance to survive" (Kamm 1993: 102; also see Kamm 2006: 62). Suppose the situation is as before, except that Joker tells Batman that if Batman chooses to save the larger group, he will kill the one member of the smaller group, but that if Batman chooses to save the smaller group, he will kill one member of the

${ }^{9}$ For a similar point, see Kamm 1993: 120.

${ }_{10}$ Cf. Sanders 1988, 5n, though Sanders does not claim that these differences don't matter. Also see Wasserman and Strudler 2003: 87-88, where they give a similar sort of example that is supposed to show that nonconsequentialists should adopt EGC in certain veil of ignorance cases, and Kamm 1993: 121, where she claims that we should save the greater number even when we know that someone never had a chance to be in the larger group. 
larger group and chop off the other's finger. At noon, Batman should save the larger group. Each hostage, desiring to keep his or her finger attached if he or she survives the ordeal, prefers that he make that decision. And as before, there is no reason for Batman to change his mind at 1:00 if the Joker loses the form in the interim. ${ }^{11}$

Some of Kamm's remarks about veil of ignorance reasoning suggest she might like to turn my modus ponens into a modus tollens. Kamm says that veil of ignorance reasoning gives incorrect results in the following case:

Suppose we can either save A or save B and also cure C's sore throat. It shows inadequate concern for the loss to A of her chance to survive - given that from her point of view she is not indifferent between her survival and someone else's - to deprive her of her chance in order to achieve a small additional utility to C. (Kamm 1998: 941)

We must change the Batman example slightly to fit Kamm's sore-throat example. Suppose Alice, Bob and Carol all have sore throats. The Joker gives Batman the following choice at noon: "I will randomly choose two of the hostages to put on opposite sides, left and right. One of those two will be killed, and the other will live. The third will live no matter what. You must decide, now, by filling out this form, whether to save the person on the left ("Lefty") or the person on the right ("Righty"). If you save Righty, I'll cure the third's sore throat." Batman should, I presume, choose to save Righty. Perhaps this is not obvious, since the hostages will only slightly prefer that he do so (only slightly preferring to have their sore throats cured). After Batman's choice, Alice is placed on the left and Bob on the right. Then the Joker loses the form. Kamm thinks it is wrong, at 1:00, for Batman to choose to save Bob and cure Carol's sore throat. The sore throat cannot break the tie; rather, a coin should be flipped. But again, it seems there is no reason for Batman to fill out the form differently at 1:00.

If Kamm is right, one of the premises of my argument must be false. Which premise could be rejected? Each premise seems true. If Kamm's intuitions concerning fingers and sore throats are undermined, so be it. Those wishing to resist the extension of the argument to fingers and sore throats have the burden of rejecting a premise.

What about cases in which the number of people in each group is the same, but the benefit each would get by being saved would be different? The story must be told somewhat differently. The Joker has captured only two hostages, Deke and Edna. He tells Batman the following: "I'm going to kill one of these two hostages. You must decide which one I will kill; otherwise I will kill both, and kill you and your dog too. Before I carry out the killing, I

11 Kamm thinks things change if it is an arm or leg, rather than a finger, that is at stake. In that case, she thinks a weighted lottery is appropriate (Kamm 1993: 102). It should be obvious that if her intuition about the Finger Case has been refuted, so have her intuitions about the Arm Case and the Leg Case. 
am going to give one of them a million dollars, which would vastly improve the recipient's quality of life, should he or she survive. Call that person 'Richie,' and the other one 'Pat.' As always, your decision will be made by filling out a form, indicating whether it is Richie or Pat who will be killed."

Perhaps it is somewhat less clear what Batman should do in this story than it is in the original story. But it certainly seems that Deke and Edna would prefer that Batman choose to save Richie, if they are rational. Whatever choice Batman makes, Deke and Edna have a 50 percent chance of survival, but if he saves Richie, each additionally gets a 50 percent chance to have a much better life. One would think that those who find EGC plausible would also find it plausible, on the same general grounds, that we should give people equal greatest chances of receiving goods other than survival, such as large amounts of money and well-being. If so, then Batman should save Richie, since doing so gives each person an equal greatest chance of survival, and also an equal greatest chance at the better future. The other relevant options (flip a coin or save Pat) give Deke and Edna an equal greatest chance of survival but not of the better future. If Joker loses the form after the random assignment of (say) Deke to the Richie role, there still seems to be no reason for Batman to change his mind. So if Batman should save Richie before it's determined who Richie is, he should still save Richie even after it's been determined that Deke is Richie. This suggests that, at least sometimes, it is permissible (or even obligatory) to use the value of a person's future as a basis for deciding whom to save.

\section{Conclusion}

I claim to have established SGN, and to have shown that EGC and its ilk are false. Similar reasoning establishes similar conclusions concerning whether coin-flipping or other random processes are justified in cases involving not only people's lives, but sore throats and welfare improvements.

My arguments have been based entirely on a certain sort of example. None of my arguments essentially employs any general principle of morality; rather, I've argued that, in these cases, Batman should behave a certain way before the coin flip and, in these cases, it would be crazy for him to change his mind. This is sufficient to show the falsity of EGC and the other randomizing principles as general principles applying to cases such as this. But it remains open for the defenders of coin-flipping or wheel-spinning to claim that their principles are true of some subset of cases that does not include cases like the ones I have been describing. The challenge is to explain why the cases I've described are importantly different from the sorts of cases where coin-flipping or wheel-spinning is required. I've given reasons, in Section 3, to be skeptical that this challenge can be met. While examples involving Batman and the Joker are farfetched, they seem to be similar, in respects that are morally relevant, to the examples discussed in the literature. If this is right, then it is simply a mistake to think that there is anything fundamentally 
unfair about making decisions based on the number of people who will be saved, or about letting well-being facts tip the scales.

Flipping coins as part of a moral decision-making process might sometimes be justified. It might relieve mental anguish on the part of the decisionmaker. Society might feel more secure knowing that the secret biases of decision-makers cannot influence their behavior in certain instances. ${ }^{12}$ These utilitarian justifications for coin-flipping are untouched by my arguments. But there is no further value, from the standpoint of fairness or justice, to flipping a coin.

Ben Bradley

Syracuse University

Department of Philosophy

wbradley@syr.edu

12 See Broome 1984, 41 for these and other justifications for choosing randomly. 


\section{References}

Broome, J. 1984. "Selecting People Randomly.” Ethics 95: 38-55.

Hirose, I. 2001. "Saving the greater number without combining claims." Analysis 61: 341-42.

Hirose, I. 2007. "Weighted Lotteries in Life and Death Cases." Ratio 20: 45-56.

Kamm, F. 1993. Morality, Mortality, Vol. 1: Death and Whom to Save from It. New York: Oxford University Press.

Kamm, F. 1998. Precis of Morality, Mortality, Vol. 1: Death and Whom to Save from It. Philosophy and Phenomenological Research 58: 939-45.

Kamm, F. 2000. "Nonconsequentialism." In The Blackwell Guide to Ethical Theory, ed. H. LaFollette, 205-26. Oxford: Blackwell Publishers.

Kamm, F. 2006. Intricate Ethics: Rights, Responsibilities, and Permissible Harm. Oxford: Oxford University Press.

Kumar, R. 2001. "Contractualism on Saving the Many." Analysis 61: 165-70.

Lawlor, R. 2006. "Taurek, Numbers, and Probabilities." Ethical Theory and Moral Practice 9: 149-66.

Otsuka, M. 2000. "Scanlon and the claims of the many versus the one." Analysis 60: 288-93.

Rawls, J. 1971. A Theory of Justice. Cambridge, MA: Harvard University Press.

Sanders, J. 1988. "Why the Numbers Should Sometimes Count." Philosophy and Public Affairs 17: 3-14.

Scanlon, T. 1998. What We Owe to Each Other. Cambridge, Mass.: Harvard University Press.

Taurek, J. 1977. Should the numbers count? Philosophy and Public Affairs 6: 293-316.

Thomson, J. 1990. The Realm of Rights. Cambridge, Mass.: Harvard University Press.

Timmermann, J. 2004. "The individualist lottery: how people count, but not their numbers." Analysis 64: 106-112.

Wasserman, D. and Strudler, A. 2003. “Can a Nonconsequentialist Count Lives?” Philosophy and Public Affairs 31: 71-94. 